\title{
Proactive Maintenance Model Based on the Law on Change of Mechanical Vibration
}

\author{
Goran Otić ${ }^{1}$, Goran Jovanov ${ }^{2}$, Živoslav Adamović ${ }^{3}$, \\ Nemanja Jovanov ${ }^{1}$, Stevo Jaćimovski ${ }^{2}$
}

${ }^{1}$ Faculty of Business and Law, "Union - Nikola Tesla" University, Knez

Mihajlova 33, Belgrade 11040, Serbia; goran.otic@ppf.edu.rs, nemanja.jovanov@ppf.edu.rs

${ }^{2}$ University of Criminal Investigation and Polices, Cara Dušana 196, Belgrade 11080, Serbia; goran.jovanov@kpu.edu.rs, stevo.jacimovski@kpu.edu.rs

${ }^{3}$ University „Union-Nikola Tesla“, Faculty of Applied Sciences, Dušana Popovića 22a, Niš 18000, Serbia, zivoslav.adamovic@fpn.rs

Abstract: The basis for proactive maintenance in thermal power plants, is the analysis of the root cause of the failure, i.e. the determination of mechanism and cause of failure occurrence from the thermal power plant system. The root causes of system failures can be eliminated in this way, and the causes of failures can gradually be eliminated using an engineering approach from any assembly of device or machine. Successful proactive maintenance programs would gradually, over time, eliminate problems of the device by project-engineering solutions, which, as a consequence, would have a significantly longer device life cycle, reduced downtime and increase production capacity.

Keywords: proactive maintenance; life cycle management; life cycle costs; vibration control; reliability

\section{Introduction}

Maintenance management has been accepted as a serious issue, only after the dynamic industrial revolution during the World War II [16]. Rapid modernization and the increasing need for high yielding productivity have led to finer development and use of hi-tech and complex machines and equipment. Therefore, high cost capital is involved in the shop floor production and the occurrence of emerging and frequent failures may result in production downtime and huge losses for a company. Hansen I. H, in his paper, referred that maintenance cost can be the second largest component of a company budget, together with just energy costs [6]. So, controlled and appropriate maintenance activities are required in order to minimize the occurrence of such failures and increase the reliability of the 
company assets through effective plant maintenance practices. Today, $80 \%$ of the parameters measured are likely to be vibration based [16]. Hence, vibration monitoring and analysis are, often, the most widely used in condition based maintenance and greatly rely on instrumentation. Machine vibrations provide a lot of information concerning the condition of a machine. The measurement and analysis of the vibration response provide great deal of information relevant for defect conditions in different types of machines [13]. Vibration-based analysis techniques can be widely used for condition based maintenance because vibration spectrum can be collected for all machinery which consists of rotating or moving elements [11] [15]. Vibration analysis is one, among a number of techniques, in condition based maintenance implemented, in order to monitor and analyze certain machines, equipment and systems in a plant. Nevertheless, the primary concept behind the vibration analysis application is to monitor rotating machinery, to detect emerging problems and to eliminate the possibility of catastrophic failure. The maintenance is initiated when indicators show the sign of defects in the initial stages. In simple words, the main criterion is to maintain the right equipment at the right time. The practice of CBM (Condition Based Maintenance) is implemented by collecting and analyzing the real time data, so that maintenance activities and resources can be prioritized/ optimized accordingly [10]. Basic advantages of proactive maintenance lie, mainly, in reducing maintenance costs (direct and indirect) and increasing the efficiency (reliability and availability) of technical systems.

Therefore, the primary goal of proactive maintenance is to increase efficiency (certainty and reliability), i.e. reduction of downtime, which results in high utilization rates and thus also the productivity.

\section{Model of Predictive Vibro-diagnostic Maintenance}

Predictive Maintenance $(\mathrm{PdM})$ is a proactive maintenance approach that emphasizes the forecast of how and when equipment will fail through data analytics, and performs maintenance precisely, before total failure occurs. This is achieved through the detection of possible failures by monitoring and analyzing various equipment operation variables, by using the assortment of diagnostic sensors and other monitoring instruments. For example, monitoring equipment changes regarding: vibration, temperature, pressure or voltage, to mention a few of these. The outcome then, is that maintenance will only be scheduled when a failure has been detected, rather than when equipment is perceived to require maintenance. Preventive Maintenance (PM), is the maintenance philosophy of performing maintenance tasks at predetermined intervals, using triggers. These triggers can be derived by a specific amount of calendar days or when a tool has elapsed a defined period of runtime [5]. Microsoft has published a predictive maintenance dataset in the past, which is designed to be used within their Azure 
platform as a learning device [9]. This dataset satisfies the need to be relevant and usable, for the development of and training for predictive maintenance model, as it has been created with that purpose in mind. However, caution should be taken when directly comparing the results of this project with other predictive maintenance solutions, as although this 'simulated' dataset provided by Microsoft is publicly available, there is no credibility that this dataset will represent realistic data values. Nonetheless, it is a valid dataset for the development of a predictive maintenance algorithm. Reliability-Centered Maintenance (RCM) is a hybrid maintenance philosophy, combining the use of PdM and Run-to-failure maintenance (RTF). RCM acknowledges that not all equipment has the same level of importance and takes a systematic approach to identify the right strategy, for the right need. Despite this, the predominant strategy is PdM, which is applied to the most critical systems of operation, while RTF is utilized for the least. [13].With supervised learning as the selected learning model, the attention must now be paid to the available supervised learning algorithms that will be used to map the predictive maintenance input and output. But first, supervised learning algorithms are prone to two specific modelling errors called 'Over fitting' or 'Under fitting' a predictive model. Furthermore, supervised learning algorithms also suffer a modelling problem called the 'Bias-variance trade-off'. These two specific circumstances need to be discussed, due to the fact that either of these modelling errors occur during the development of the predictive maintenance model [13]. Prior to the completion of the algorithmic procedure, it is necessary to check whether the solution variant meets the set criteria and limitations. If these are not satisfied, they must be rejected. This is particularly problematic at the failures belonging to the categories in which the costs represent project limitation, as it may be required to accept necessary solution that carries within itself higher risk for failure appearance. The completion of a procedure defined by general algorithm of preventive installation represents the end of analysis of all predicted variant solutions. It is then when it should be transferred to the decision on specific variant solution. Defined goal function in our specific example is the selection of optimal vibro-diagnostic formats set which provides the maximum possibility of dynamic problem detection, selection and verification, together with economic justification and simplicity of use. However, it is possible to conclude that the existence of dynamic problems is a characteristic for certain types of rotating machines, which could be categorized in particular groups depending on nominal power, speed, type of foundation, etc. The proposed solution advocates for soft sensor based algorithms. The soft sensor algorithms provide information about the physical status of the components, as well as information about the performance of the systems. These algorithms take advantage of existing or available internal signals of the systems. The objective is to estimate inaccessible states and parameters of the systems using as few physical sensors as possible to acquire the necessary signals to work with. 


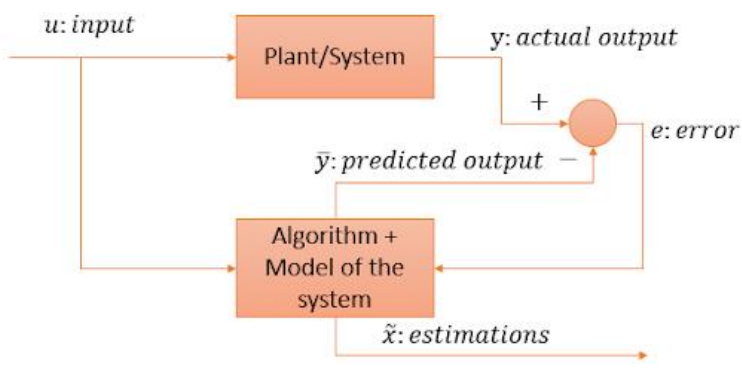

Figure 1

Soft sensor algorithm basic diagram

Many strategies for transitioning to condition-based maintenance leverage the Industrial Internet of Things (IIoT). However, organizations should first take advantage of existing operations' data sources, before investing in IIoT-enabled sensors or software. Capitalizing on the billions of data points already being generated by SCADA and automation systems augments maintenance records front-line workers use daily.

\subsection{Stages in the Vibration Control Process}

Condition Monitoring systems are the main technical reliability systems. These systems allow for the management of individual assets based on conditions. There is a wide array of available measurement technologies from portable systems to continuous on-line systems with permanently mounted transducers. Through effective monitoring, the technologies allow fault identification, diagnosis, and sometimes prognosis. Vibration signatures of the machine can offer an early warning to the operator for time based maintenance or to make a crucial decision before any serious problem or unscheduled downtime. The amplitude of the vibration signature gives an indication of the severity of the problem, whilst the frequency can indicate the source of the defect [12]. A system of vibro-diagnostics is basically a system which includes:

1) Establishing the laws for changing the parameters of the machine condition and its suitability for control.

2) Selection of vibration parameters and determination of characteristics of their changes and connections with machine condition parameters.

3) Determination of vibration parameter norms.

4) Determining the possibility of diagnosis setting.

5) The choice and technical-economic rationale of relevant method and measurement instrument.

6) Determining the optimal vibration control procedure or algorithm of vibration control (Fig. 2). 


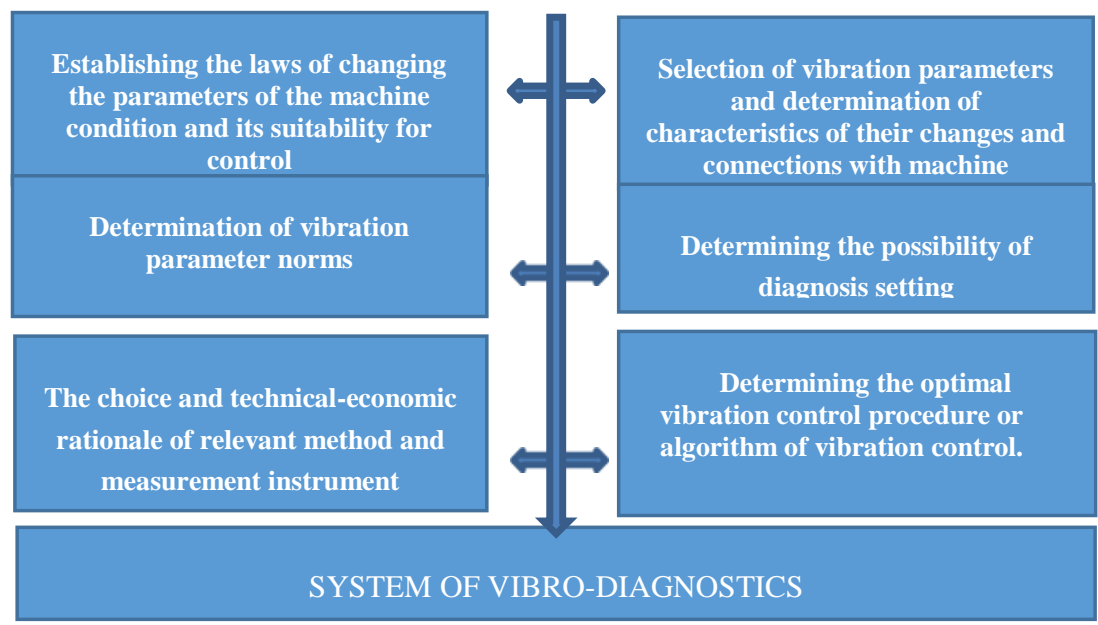

Figure 2

System of vibro-diagnostics

Except for the above mentioned, for the organization of vibration control process the following is required: the mode, technology, location and position of vibration control in the general maintenance system, bearing in mind the basic structure of diagnostics with control and levels of vibration.

\section{Vibration Acceptance and Testing Criteria}

It is highly recommended that equipment acceptance testing is performed on completely new and newly rebuilt hardware. The testing efforts should include the following:

1) Vibration measurements on each bearing in two radial directions and the axial direction (i.e. 12 measurements per four-bearing machine).

2) Vibration measurements at each hold-down bolt location.

3) Measurements of velocity and high frequency energy (spike energy or ESP) in rolling element bearing machines and velocity and displacement in sleeve bearing machines.

4) Measurements should be taken with the unit under a loaded condition (at least $70 \%$ load when possible). Uncoupled motor data is not acceptable for acceptance testing.

Vibration measurement is an effective, reliable and non- intrusive technique which monitors the condition of the machine during startups, shutdowns and normal operations [1]. Periodicity and scope of work for technical diagnostics are planned, while the foreboding character is provided through continuous monitoring of technical condition of the system with the aim to detect the prefailure condition $\left(\varepsilon_{1}\right)$ and the limit of deterioration $\left(\varepsilon_{2}=\varepsilon_{\max }\right)$. 
If the condition parameter reaches $\varepsilon_{1}$, this means that appropriate maintenance activities should be performed to avoid system failure (perform replacement or repair of the system component at the moment of diagnostic control at $\varepsilon \geq \varepsilon_{1}$ ). Thus, the measurement of advancing tolerance $\left(\Delta \varepsilon=\varepsilon_{2}-\varepsilon_{1}\right)-$ connected to the measurement of periodicity of diagnostic control $\left(\Delta \boldsymbol{T}=\mathrm{T}_{2}-\mathrm{T}_{1}\right)$.

Therefore, proactive maintenance strategy is a set of rules for determining the regime of diagnostics of system components in the real process of exploitation and making decisions on the necessity for their replacement or for necessary volume of maintenance, based on the information on real technical condition of system.

The best variant solution for specific technical system defines specific model of vibro-diagnostics maintenance (Fig. 3).

\subsection{The Method of Data Collection and Processing}

The controls and measurements of vibrations of turbine bearing housing, as well as of the bearing clearance of the turbo-generator's turbine have been performed in "Smederevo Stell Mill". The mentioned measurements are performed by diagnostics devices where the measurement results are automatically processed by a program application and stored in the main maintenance system program. The measurements of bearing clearance have been performed with standard etalons - tickets.

The control and measurements are performed 4 times a year.

For the mentioned research, the diagnostic parameters data of the vibration value of turbo-generator's turbine bearing housing have been used, at which increased values of bearing clearance appeared within a period of two years, i.e. the data from 8 controls have been used.

Mathematical expectation $\mathrm{m}_{\varepsilon}(\mathrm{t})$ and standard deviation $\varepsilon(\mathrm{t})$ are approximated by line functions. When determining the correlation coefficient, correlation theory method has been used. 


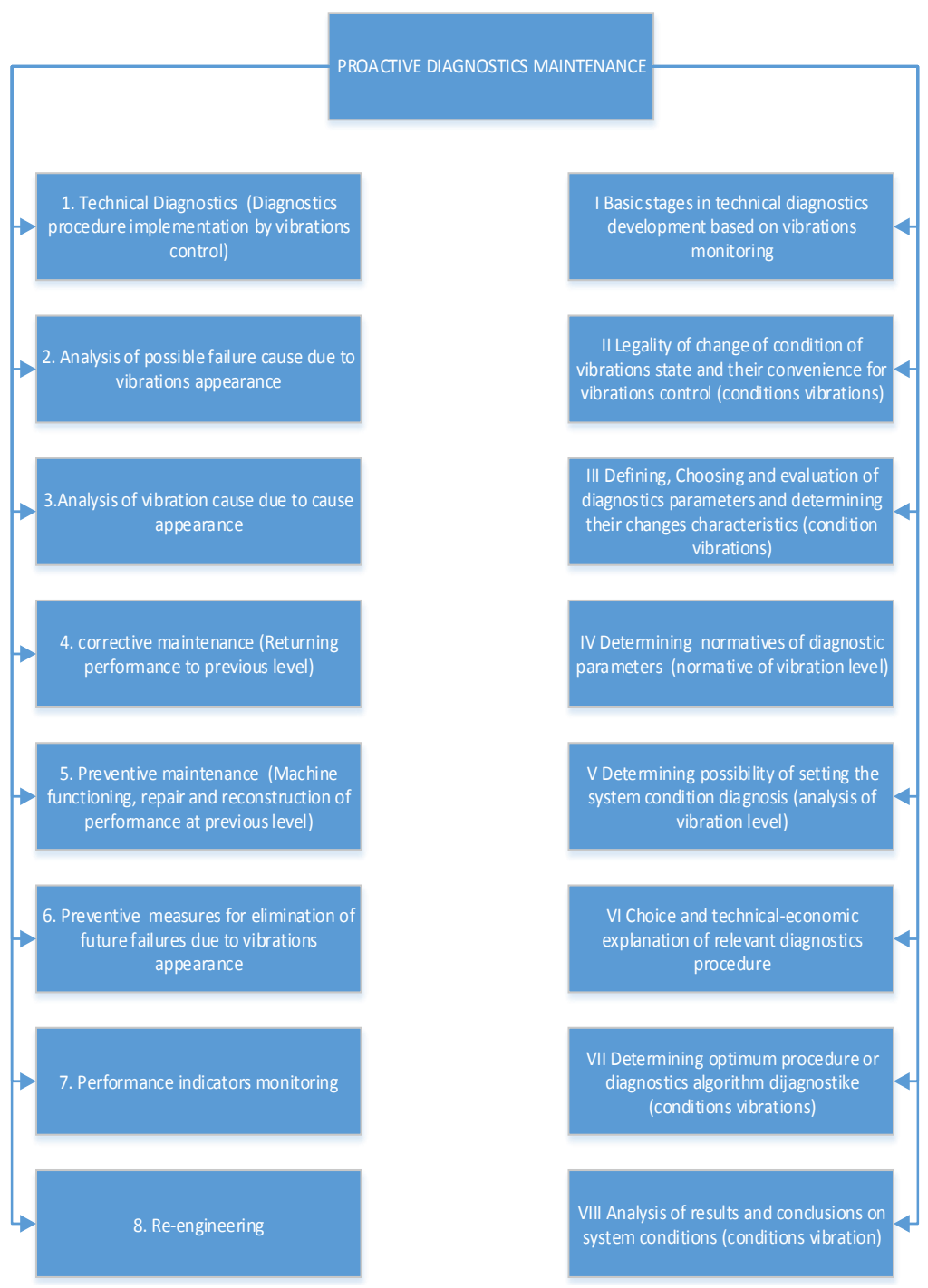

Figure 3

Model of proactive diagnostic maintenance 


\section{Methodology}

Change of structural parameters and thus, the change of technical condition is random process that is performed under the influence of a wide range of exploitation factors. This process can fully be described by the density of the distribution of condition parameters $\mathrm{f}(\varepsilon, \mathrm{t})$ at any moments of time. It is adopted here that $\mathrm{f}(\varepsilon, \mathrm{t})$ obeys the normal law of distribution.

At same-type components and/or systems, the parameters of technical condition reach the limit value (deterioration limit $\varepsilon_{2}$ ) at different moments of time. In this way, the density of distribution of condition in failure $\varphi\left(t, \varepsilon_{2}\right)$ is formed. Here too, it is adopted that $\varphi\left(t, \varepsilon_{2}\right)$ obeys the normal law of distribution.

To determine the equation linking the distribution density functions $f(\varepsilon, t)$ and $\varphi(t$, $\varepsilon_{2}$ ), we use Figure 4, where we adopt a linear change of system condition.

$P\left\{t_{x} \leq T_{i}\right\}_{\varepsilon_{1}}=P\left\{\varepsilon>\varepsilon_{2}\right\}_{T_{2}}$

i.e. using known laws from probability theory, the following equations can be written:

$\int_{\varepsilon_{1}}^{\varepsilon_{2}} f\left(\varepsilon, T_{2}\right) d x=\int_{T_{1}}^{T_{2}} \varphi\left(t, \varepsilon_{1}\right) d t$

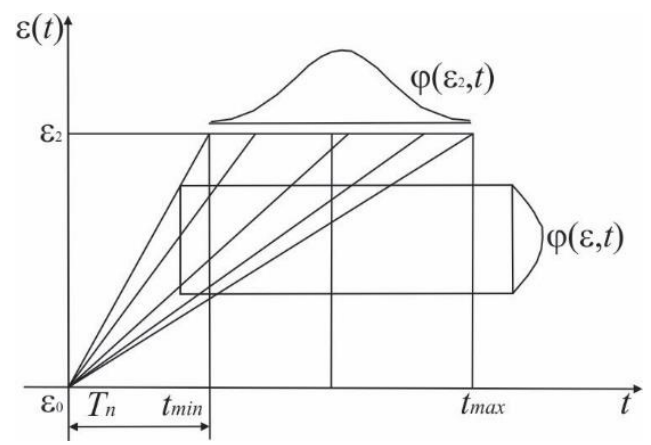

Figure 4

Correlation of parameters of technical condition and technical condition of system and after sorting mathematical model can be obtained

Therefore, it can be concluded that monotonic process $\varepsilon(\mathrm{t})$ with given $\mathrm{T} 1$ and $\varepsilon_{2}$, following the moment of the diagnostic control $T_{2}$ and the pre-critical level $\varepsilon_{l}$, satisfies the last equation for general conditions of technical exploitation of the system.

During the real exploitation process, all values of $\varepsilon\left(t_{x}\right)$ will be grouped around the mean value of $\varepsilon\left(t_{x}\right)$ and will have diffusion around it expressed by standard deviation (standard deviation appears due to frequent starting and stopping of the system, due to different modes of exploitation process, etc.). 
Now, the equation can be provided, which fully describes the model of change of parameters with the use of confidence intervals

$\varepsilon(\mathrm{t})=\mathrm{u} \cdot \mathrm{t}+\varepsilon_{0} \neq \sigma_{\text {tot }}$

where:

$u$ - condition change speed $\left(\mathrm{u}=\frac{\mathrm{d} \varepsilon}{\mathrm{dt}}\right)$

$\varepsilon_{0}-$ minimum value of condition parameter

Having in mind that given confidence level is $p_{z}=R_{z}$, and the allowed probability of failure occurrence $p_{0}=1-p_{z}$ can be written for some point of time $t_{z}$

$\mathrm{p}_{0}\left(\mathrm{t}_{\mathrm{x}}\right)=\int_{0}^{\mathrm{t}_{\mathrm{x}}} \varphi\left(\mathrm{t}_{\mathrm{x}}, \varepsilon_{2}\right) \mathrm{dt}=\frac{\Phi\left(\varepsilon\left(\mathrm{t}_{\mathrm{x}}\right)-\varepsilon_{2}\right)}{\sigma_{\text {tot }}}$

where:

$\Phi-$ Gaussian function, and

$\varepsilon\left(t_{x}\right)$ - mean value of condition change

Therefore, the following equation results:

$\int_{0}^{\mathrm{T}_{1}} \varphi\left(\mathrm{t}, \varepsilon_{1}\right) \mathrm{dt}=\int_{\mathrm{T}_{1}}^{\mathrm{T}_{2}} \varphi\left(\mathrm{t}, \varepsilon_{2}\right) \mathrm{dt}$

Which can help in explaining the physical meaning of mentioned theorem, depending on whether it is a continuous or periodic diagnostic control.

For normal law of change of conditions parameters, the mathematical expectation mc (t) and mean square deviation $\sigma_{\varepsilon}(t)$ are approximated by linear dependences:

$\mathrm{m}_{\varepsilon}(\mathrm{t})=\mathrm{m}_{\mathrm{a}}+\mathrm{m}_{\mathrm{b}} \mathrm{t}$

$\sigma_{\varepsilon}(\mathrm{t})=\sigma_{\mathrm{a}}+\sigma_{\mathrm{b}} \mathrm{t}$

Where $\mathrm{m}_{\mathrm{a}}$ and $\sigma_{a}$, and parameters of technical condition at the moment $t=0$, and represent the deviation of condition parameters from its initial value $\varepsilon_{0}$, which may be constructively allowed deviation (e.g. the initial gap in sliding pitch). Such approximation will be of great use at determining the ratings of diagnostic controls.

Now the density of distribution $f\left(\varepsilon, t_{2}\right)$ can be determined according to [1]:

$\mathrm{f}\left(\varepsilon, \mathrm{t}_{2}\right)=\frac{1}{\sqrt{2 \pi}\left(\sigma_{\mathrm{a}}+\sigma_{\mathrm{b}} \cdot \mathrm{t}\right)} \exp \left(-\frac{\varepsilon-\mathrm{m}_{\mathrm{a}}-\mathrm{m}_{\mathrm{a}} \cdot \mathrm{m}_{\mathrm{b}}}{2 \cdot\left(\sigma_{\mathrm{a}}+\sigma_{\mathrm{b}} \cdot \mathrm{t}\right)}\right)$

It should be also stated herein that for each controlled parameter (vibration and noise level, quantity of products deteriorated in oil, etc.) it is necessary to determine the failure limits $\left(\varepsilon_{2}\right)$. 
When selecting diagnostic parameters of the system, it is necessary to determine the character of their relationship to the parameters of condition. In doing so, one or more diagnostic parameters may define only one condition parameter.

The choice of diagnostic parameters $(\rho)$ can be derived based on several basic criteria, using the following characteristics: informative, relative relationship, consent, variation and relation.

The informative nature of diagnostic parameter (or "diagnostic weight") can be estimated over the number of information on technical condition of system that contains that parameter.

Mean value of the information can be used not only to select diagnostic parameters $(\rho)$.

Max relative parameter ratio can be defined as follows:

$\mathrm{M}_{\mathrm{d}}=\frac{\rho_{\max }-\rho_{\mathrm{n}}}{\varepsilon_{2}-\varepsilon_{\mathrm{n}}}=\frac{\Delta \rho}{\Delta \varepsilon}$

Where $M_{d}$ should have the highest values possible.

The studies show that the most favorable ratio is $M_{d}>2.30$

Between the diagnostic parameters and the parameters of the technical condition, the required agreement must exist, i.e. to monotonic increase or decrease should correspond relevant change of $p$, but inversely a proportional change may occur anyways.

The variation represents the deviation of parameters from mean static value.

The correlation coefficient $r$ (in this case $r$ is the degree of connection between $\varepsilon$ and $\rho$ ) can be taken as a measure of the relationship between the diagnostic parameters and the relevant condition parameters, when solving specific tasks.

\subsection{Anticipation of the Turbo Machine Condition}

Anticipation is the prediction (forecast) of behavior of system condition parameters in the future, after performed diagnostics, with the aim to ensure the required efficiency of the exploitation process. Determining the "usability reserve" of a system is necessary in terms of its optimal reduction, as well as determining the timing of the following diagnostic condition controls or determining the moment of performing the necessary maintenance activities. Therefore, the anticipation results are the basis for decision making.

As the entry measurement in the anticipation of "usability reserve", necessary level of reliability occurs $\left(p_{z}=R_{z}\right)$, which is expressed thru quantile of normal distribution $\left(u_{1-\rho 0}\right)$, where numeric value is tabulated. 
The moment of first diagnostic condition control: can be obtained from the condition that the system meets the required reliability $\left(R_{z}\right)$.

Thus, the moment of the first diagnostic control of the condition can be obtained, after entering $f\left(\varepsilon, T_{1}\right.$, ) for normal distribution [4]:

$\mathrm{T}_{1}=\frac{1}{\mathrm{~m}_{\mathrm{b}}-\sigma_{\mathrm{b}} \mathrm{u}_{1-\rho_{0}}}\left(\varepsilon_{2}-\sigma_{\mathrm{a}} \mathrm{u}_{1-\rho_{0}}-\mathrm{m}_{\mathrm{a}}\right)$

where:

$u_{1-\rho_{0}}$ quantile of normal distribution (cumulative frequency), that corresponds to the probability of lawless $P_{z}$ for the time $T$.

Generally, the limits of diagnostics measurements can be double - alternative and anticipation of "usability reserve" (period of leftover usage).

In both cases it is necessary to determine the limit values of condition parameters.

The measures $\varepsilon_{l}$ and $\Delta \varepsilon$ can be calculated (for normal law of parameters distribution) in accordance with the expression:

$\varepsilon_{1}=\frac{\sigma_{\mathrm{a}}\left(\varepsilon_{2}-\mathrm{m}_{\mathrm{b}} \Delta \mathrm{T}\right)+\sigma_{\mathrm{b}}\left(\varepsilon_{2} \mathrm{~T}_{1}+\mathrm{m}_{\mathrm{a}} \Delta \mathrm{T}\right)}{\sigma_{\mathrm{a}}+\sigma_{\mathrm{b}} \mathrm{T}_{1} \Delta \mathrm{T}}$

$\Delta \varepsilon=\frac{\sigma_{\mathrm{a}}\left(\varepsilon_{2} \varepsilon_{\mathrm{b}}+\sigma_{\mathrm{b}} \sigma_{\mathrm{a}}-\mathrm{m}_{\mathrm{a}} \sigma_{\mathrm{b}}\right) \Delta \mathrm{T}}{\sigma_{\mathrm{a}}+\sigma_{\mathrm{b}}\left(\mathrm{T}_{1}+\Delta \mathrm{T}\right)}$

where:

$\Delta T=T_{2}-T_{1}-$ period of diagnostic controls

$T_{2-}$ moment in which the next diagnostics control

$T_{1-}$ moment of the first diagnostic control

If measured value of conditions parameters is below defined limit value, then the moment in which the next diagnostics control of condition is performed, should be looked for. This is how the expression for defining the moment of the second diagnostic control is got [3]:

$\mathrm{T}_{2}=\frac{1}{\mathrm{u}_{1}-\mathrm{p}_{0}}\left[\varepsilon_{1}+\Delta \varepsilon\left(\mathrm{T}_{1}\right)\right]$

In the moment $T_{2}$ the same procedure is repeated as in the moment $T_{1}$.

The calculation of moment of the next diagnostic control of condition $T_{2+n}$ is performed according to the equation:

$\mathrm{T}_{2+\mathrm{n}}=\frac{1}{\mathrm{u}}\left[\varepsilon_{1}+\Delta \varepsilon\left(\mathrm{T}_{1+\mathrm{n}}\right)\right]$

The process is repeated in the moment when measured value of condition parameter becomes $\varepsilon\left(T_{n}\right)>\varepsilon_{l}$. It is then when relevant maintenance activities should be performed. 
Maintenance activities, except mentioned examples, can be performed also in the case when it is required from the system to function longer than predicted by calculated moments of condition control. Such cases can be represented by the expression:

$T_{2} \geq T_{2+n}-T_{1+n}$

In negative condition, the system continues to operate in the idle state until $\mathrm{T}_{2+\mathrm{n}}$, when the next diagnostic condition check is performed.

Based on previous considerations, a system state anticipation algorithm can be provided that allows the use of $N$ diagnostic parameters, with always the lowest of $N$ possible values for the $\left(T_{1}, T_{2}, T_{2+n}\right)$ diagnostic controls selected. The calculation of condition parameters, for all diagnostic parameters, is done in moments $T_{l m i n}$, $T_{2 m i n}, T_{2+n \min .}$

\subsection{Application of the Mathematical Model of Vibro- diagnostics on the Case of Turbo-generator in Smederevo Steel Mill}

The research of basic indicators of vibro-diagnostic maintenance model were performed on the example of turbo-generator in Smederevo Steel Mill.

As diagnostic parameter, in this case, the vibrations of the turbine bearing housing (p) were selected, resulting in increased gaps in bearings.

Based on the research performed within the period of 2 years the following were selected:

$\varepsilon_{0}=115[\mu \mathrm{m}]$

$\varepsilon_{2}=155[\mu \mathrm{m}]$

$R_{Z}=0.98$

$u=0.118[\mu \mathrm{m} / \mathrm{h}]$

$u_{1-p 0}=3.8$

mathematical expectation $\mathrm{m}_{\mathrm{i}}(\mathrm{t})$ and standard deviation $\sigma_{\mathrm{i}}(\mathrm{t})$ were approximated by line functions.

The coefficients $m_{a}$ and $m_{b}$ were calculated in accordance with:

$$
\begin{aligned}
& m_{a}=\frac{t_{i+1} m_{\varepsilon}\left(t_{i}\right)-t_{i} m_{\varepsilon}\left(t_{i+1}\right)}{t_{i+1}-t_{i}} \\
& m_{b}=\frac{m_{\varepsilon}\left(t_{i+1}\right)-m_{\varepsilon}\left(t_{i}\right)}{t_{i+1}-t_{i}}
\end{aligned}
$$

The coefficients $\sigma_{\mathrm{a}}$ and $\sigma_{\mathrm{ib}}$ were calculated by analogue functions as $\mathrm{m}_{\mathrm{a}}$ and $\mathrm{m}_{\mathrm{b}}$. the estimate of mean value $\mathrm{m}$ of whole population (total quantity of replaced 
component part of the system), based on the research of limited sample, in case of normal law, was performed with the help of standardized normal distribution and with help of so called $\boldsymbol{t}$-distribution. This is how the following values were calculated:

$m_{a}=50.42$

$m_{b}=0.290$

$\sigma_{a}=17.40$

$\sigma_{b}=0.056$

In order to determine the character of dependence of parameters of technical condition from diagnostic parameter ( $\varepsilon$ to $\rho$ ), the theory of correlation was used.

As this method requires many numerical operations, a computer was used. Based on algorithms and program, from wanted correlation (in this case linear dependence) were calculated the correlation coefficients. Correlation coefficient and coefficient of regressive functions direction are as follows:

$r=0.55$

$a_{1}=1.10$

$b_{1}=0.070$

Comparing correlation functions with real values, it was determined that these were represented with enough punctuality.

The control of hypothesis on normal distribution $f\left(\varepsilon_{l}, t\right)$ in accordance with the criterion of Pearson and Kolmogorov, has shown its correspondence with examined data.

For shown parameters in accordance with the relations, the moments of the first diagnostics condition control $\left(T_{1}\right)$ have been calculated, as well as pre-critical level $\left(\varepsilon_{l}\right)$

$T_{l}=640[\mathrm{~h}] \quad \varepsilon_{l}=124[\mu \mathrm{m}]$

Having in mind that the calculated values of technical condition parameters $\left(\varepsilon\left(T_{1}\right)\right)$ are less than pre-critical condition $\varepsilon_{l}$, the turbine continued the process of exploitation without performing maintenance activities.

The first moment of diagnostics control for bearing as a whole is determined from the conditions $T_{1}=\min \left(T_{1}\right)$. The adopted value is $T_{1}=790$ hours. The moment of the next diagnostic control T2 is calculated according to the formula and is $T_{2}=$ 3436 hours. For the measured values of diagnostic parameter at the moment $T_{2}$, the technical state parameter $\left(\varepsilon\left(T_{2}\right)\right)$ was calculated.

$p\left(T_{2}\right)=134[\mu \mathrm{m}]$

$\varepsilon\left(T_{2}\right)=141[\mu \mathrm{m}]$ 
For the determination of the value of required interval $T_{2}=2360$ hours, $T_{2}=T_{2}$ $T_{1}=2620$ has been obtained, which means that it was necessary to perform the planned maintenance activities at the moment $T_{2}=3428$ hours (the lowest $T_{2}$ is adopted). After this maintenance model has been developed in accordance with the condition for turbine bearing, the maintenance workforce hiring cost has been reduced and the availability of the system has been increased. The developed program is universal and can be used on $\mathrm{N}$ different diagnostic parameters for different technical systems.

\subsection{Optimization of Cost of Vibration Diagnostics and Failures of Technical Systems}

The essence of this submodel is that it is possible to calculate the optimal interval for the vibration diagnostics of technical systems with high malfunction costs $\left(n_{\text {opt }}\right)$, which is often the case in thermal power plants and hydropower plants. Total malfunction costs of failure of technical $T_{T}$ systems decrease at the beginning, and later they increase (Fig. 5), while the costs of diagnostics $T_{D}$ increase with the increase of vibration interval between two vibration diagnostics.

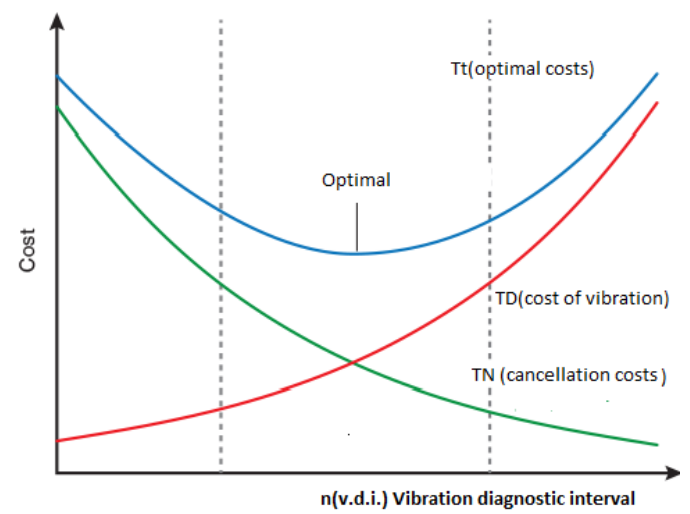

Figure 5

Total costs of vibration diagnostics and malfunctions of technical systems

From this graph, the optimal point in terms of costs and number of failures can be identified within the center of the intelligent maintenance sector; intelligent maintenance can be realized with an online condition monitoring solution [9].

Total costs of $T_{T}$ malfunctioning of technical systems occur as the sum of average costs: $T_{C}$ vibration diagnostics, $T_{D}$ malfunction, $T_{R}$ maintenance and $T_{L}$ outage due to the vibration diagnostics process.

The sum of all average costs is:

$\mathrm{T}_{\mathrm{T}_{\mathrm{T}}}=\mathrm{T}_{\mathrm{C}}+\mathrm{T}_{\mathrm{D}}+\mathrm{T}_{\mathrm{R}}+\mathrm{T}_{\mathrm{L}}=\frac{\mathrm{T}_{\mathrm{C}}}{\mathrm{n}}+\frac{\mathrm{n}+1}{2} \frac{\mathrm{T}_{\mathrm{D}}}{\mathrm{n}_{\mathrm{R}}}+\frac{\mathrm{T}_{\mathrm{R}}}{\mathrm{n}_{\mathrm{R}}}+\frac{\mathrm{n}_{\mathrm{L}} \mathrm{T}_{\mathrm{L}}}{\mathrm{n}_{\mathrm{R}}}[$ euro/piece $]$ 
where: $n$-vibration diagnostic interval

$n_{R}$ - estimated number of technical systems between immediate vibration diagnostics

$n_{L}$ - number of missed technical systems in process interruption due to vibration diagnostics

It is evident that $T_{T T}$ has a continuous flow and all derivatives, so its minimum value can be calculated with optimal vibration diagnostic interval, usingrequired condition for calculating extremes with the first derivative of the function.

$\frac{d T}{d n}\left(\frac{T_{C}}{n}+\frac{n+1}{2} \frac{T_{D}}{n_{R}}+\frac{T_{R}}{n_{R}}+\frac{n_{L} T_{L}}{n_{R}}\right)=-\frac{T_{C}}{n^{2}}+\frac{T_{D}}{2 n_{R}}$

by equalizing the first derivative of the function with zero and with sufficient condition that the second function derivate is greater than zero, the optimal vibration diagnostics interval is obtained.

$\mathrm{n}_{\mathrm{opt}}=\sqrt{\frac{2 \mathrm{n}_{\mathrm{R}} \mathrm{T}_{\mathrm{C}}}{\mathrm{T}_{\mathrm{D}}}}$ [piece]

optimal total malfunction costs are now obtained [9].

$\mathrm{T}_{\mathrm{T}}=\sqrt{\frac{2 \mathrm{~T}_{\mathrm{C}} \mathrm{T}_{\mathrm{D}}}{\mathrm{n}_{\mathrm{R}}}}+\frac{\frac{\mathrm{T}_{\mathrm{D}}}{2}+\mathrm{T}_{\mathrm{R}}+\mathrm{n}_{\mathrm{L}} \mathrm{T}_{\mathrm{D}}}{\mathrm{n}_{\mathrm{R}}}$

The last expression is missing the measurement for repairs $T_{R}$, so the optimal interval will not be correctly determined.

At successive diagnostics of vibrations, the probability of occurrence of the $1^{s t}$, $2^{\text {nd }}, 3^{\text {rd }}$ and $n$-th malfunctioning technical systems are mutually equal (Fig. 6)

$(k-1)$ th diagnostic

$k$-th diagnostic

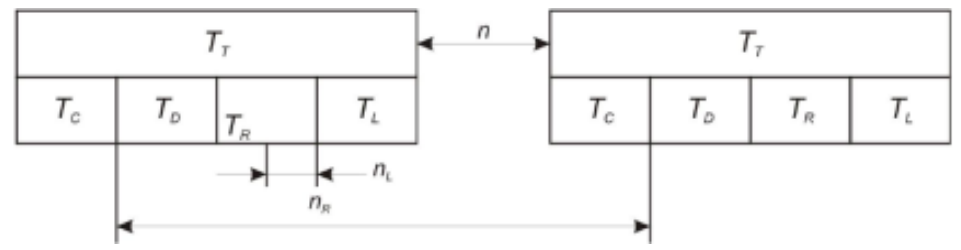

Figure 6

Cost ratio and number of technical systems for successive vibration diagnostics

When malfunctioning technical system is found to be in k-th vibration diagnostics, it causes the occurrence of malfunctioning technical system between $(k-1)$ th and $k$-th diagnostic vibration, and therefore the average number of malfunctioning technical systems is $n / 2$. Now the actual number of technical systems is between two consecutive settings $\left(n_{R}+n / 2\right)$ instead of $n_{R}$. 
Based on that:

$\mathrm{T}_{\mathrm{T}} \cong \frac{\mathrm{T}_{\mathrm{C}}}{\mathrm{n}}+\left(1-\frac{\mathrm{n}}{2 \mathrm{n}_{\mathrm{R}}}\right)\left(\frac{\mathrm{n}+1}{2} \mathrm{~T}_{\mathrm{D}}+\mathrm{T}_{\mathrm{R}}+\mathrm{n}_{\mathrm{L}} \mathrm{T}_{\mathrm{D}}\right)$

After the second derivative (greater than zero) $d T_{T} / d n$, the optimal interval is obtained for vibration diagnostics of technical systems with high malfunctioning costs:

$\mathrm{n}_{\mathrm{opt}}=\sqrt{\frac{2 \mathrm{~T}_{\mathrm{C}}\left(\mathrm{n}_{\mathrm{R}}+\mathrm{n}_{\mathrm{L}}\right)}{\mathrm{T}_{\mathrm{D}} \frac{\mathrm{T}_{\mathrm{R}}}{\mathrm{n}_{\mathrm{R}}}}}$

For the period of 2 years:

$T_{N}=470000$ euro

$T_{D}=490000$ euro

\section{Conclusions}

Predictive maintenance requires predictions that are reliable. Examination of vibration phenomenon provides us with the data concerning the volume of working parameters changes and the intensity of vibrations.

On the basis of the obtained results, we evaluate the safety. Often cited, in most cases, it is necessary to determine the cause of non-stationary occurrences that should be either removed or amortized. Working ranges that should be avoided are also determined in many cases.

The primary sources of vibrations for rotating pumps are mechanical, hydraulic and electric processes, caused by the design, manufacturing technology, working regime and exploitation.

The primary goal of proactive maintenance is to find degradation mechanisms which lead to the failure of some elements.

Compared to predictive maintenance, i.e. the maintenance by condition, proactive maintenance does not imply determination of the stage in which an element will fail (what its remaining useful life cycle is), but it tries to discover the mechanism that leads to failure, to mitigate it or to completely eliminate it, in order for the life cycle of an element to be optimally prolonged.

Therefore, the goal is to delay at maximum, or even to completely eliminate, the failure occurrence. Quality issues can hardly be solved without knowledge and an operating knowledge management system. In order to fulfill strategic goals, it is worthwhile to only take quality efforts into consideration [2].

\section{References}

[1] Adamović, Ž., Josimović, LJ., Vulović, S., Ilić, B., Spasić, D.: Vibrodiagnostic Maintenance of Technical Systems, Serbian Society for 
Technical Diagnostics Adam institute, Smederevo, 2016, ISBN-978-8683701-39-1

[2] Bencsik, A., Horváth-Csikos G.: The Role of Knowledge Management in Developing Quality Culture: Acta Polytechnica Hungarica, Vol. 15, No. 8, 2018

[3] Diewald, W., Nordmann, R.: Parameter Optimization for the Dynamics of Rotating Machinery, Proceedings of the Third IFToMM International Conference on Rotordynamics, Lyon, France, 1990

[4] Gunter, E.: Understanding amplitude and phase in rotating machinery, Vibration instittute 33Annual Meeting, Harrisburg, PA., June 23-27, 2009

[5] Geissbauer, R., Vedso, J., Schrauf, S.: '2016 Global industry 4.0 survey', industry 4.0: Building the digital enterprise, 2006, https://www.pwc.com/gx/en/industries/industries-4.0/landingpage/industry-4.0-building-your-digital-enterprise-april-2016.pdf

[6] Hansen, I. H.: Performance Measurement of the Maintenance Function Within Ecomold Ltd Master thesis in Industrial Economy and Information Management, Agder University College, Grimstad, 2006, https://uia.brage.unit.no/uia-xmlui/bitstream/handle/11250/138332/ Hansen.pdf? sequence $=1$ \&isAllowed=y

[7] Lifson, A., Simmons, H. Smalley, A.: Vibration Limits for Rotating machinery, Mechanical Engineering, pp. 60-65, 1987, ISSN: 0025-6501

[8] Ličen, H., Zuber, N.: Predictive maintenance of rotating equipment based on vibration measurements and analysis, Technical Diagnostics journal, VI/No. 1, Belgrade, 2007

[9] Mauntz, M., Peuser, J.: Identification of Critical Operation Conditions of Industrial Gearboxes by 24/7 Monitoring of Oil Quality, Oil Aging, and Additive Consumption, $6^{\text {th }}$ International Conference on Fracture Fatigue and Wear, IOP Conf. Series: Journal of Physics: Conf. Series 843, 2017

[10] Morales, D., K.: CBM Policy Memorandum. Washington DC: Deputy under Secretary of Defense for Logistics and Material Readiness, 2002

[11] Muszynska, A.: Vibrational Diagnostics of Rotating Machinery Malfunctions, International Journal of Rotating Machinery, Vol. 1, No. 3-7; Amsterdam, 1995

[12] Peng, Z, Kessissoglou, N.: An integrated approach to fault diagnosis of machinery using wear debris and vibration analysis, Wear 255(7):pp. 12211232,2003

[13] Curran, K., King, R.: Predictive Maintenance for Vibration-Related Failures in the Semi-Conductor Industry, Comput. Eng. Inf.Technol, 8:1 Journal of Computer Engineering \& Information Technology, 2019 
[14] Scheffer C, Girdhar P: Practical machinery vibration analysis and predictive maintenance. Elsevier, Amsterdam, 2004, ISBN-9780750662758

[15] Vulović, S.: Integrated maintenance model based on the change establishment of principles of Mechanical vibrations change and its impact on prognosticis of condition of rotor engines ( $\mathrm{PhD}$ dissertation), University in Novi Sad, 2018, www.cris.uns.ac.rs

[16] Vyas, R. K., \& Pophaley, M.: Plant maintenance management practices in automobile industries: A retrospective literature review, Journal of Industrial Engineering and Management, pp. 512-541, 2010, ISSN: 20138423 